\title{
Evolution of a synoptic-scale vortex advecting toward a high mountain
}

\section{Journal Article}

Author(s):

Schwierz, Cornelia B.; Davies, Huw C.

Publication date:

2003

Permanent link:

https://doi.org/10.3929/ethz-b-000056897

Rights / license:

Creative Commons Attribution 4.0 International

Originally published in:

Tellus A: Dynamic Meteorology and Oceanography 55(2), https://doi.org/10.3402/tellusa.v55i2.12091 


\section{Evolution of a synoptic-scale vortex advecting toward a high mountain}

\section{Cornelia B. Schwierz \& Huw C. Davies}

To cite this article: Cornelia B. Schwierz \& Huw C. Davies (2003) Evolution of a synoptic-scale vortex advecting toward a high mountain, Tellus A: Dynamic Meteorology and Oceanography, 55:2, 158-172, DOI: 10.3402/tellusa.v55i2.12091

To link to this article: https://doi.org/10.3402/tellusa.v55i2.12091

\section{(c) 2003 Blackwell The Author(s). Published by Taylor \& Francis.}

\section{Published online: 15 Dec 2016.}

Submit your article to this journal $匚$

\section{Џ Article views: 25}

Q View related articles $\sqsubset$

7 Citing articles: 1 View citing articles 진 


\title{
Evolution of a synoptic-scale vortex advecting toward a high mountain
}

\author{
By CORNELIA B. SCHWIERZ and HUW C. DAVIES*, Institute for Atmospheric and Climate Science, \\ ETH Zürich, Switzerland
}

(Manuscript received 26 October 2001; in final form 2 July 2002)

\begin{abstract}
A model-based study is undertaken of a synoptic-scale vortex's encounter with Greenland-scale topography. The ambient setting is a barotropic westerly flow of uniform potential vorticity. This flow is both incident upon and induces an anticyclone over the topography, and it also serves to advect the vortex toward the mountain. In a simulated evolution of the flow the vortex circumnavigates poleward around the mountain but concomitantly undergoes significant dissolution on the windward side followed by a substantial reconstitution to the lee. It eventually advects away downstream as a compact vortex of reduced amplitude. This sequence of events is interpreted in terms of the combined influence of the orographic anticyclone and the self-dynamics of the vortex.
\end{abstract}

\section{Introduction}

Extra-tropical synoptic-scale cyclonic systems occur preferentially within and travel along quasilongitudinally aligned storm tracks. In the Northern Hemisphere the two major tracks are located over the Atlantic and Pacific, and hence as a vortex-like cyclonic system evolves it can encounter major topographic features such as Greenland and the Scandinavian Mountains, or the Rocky Mountains. Likewise in the Southern Hemisphere cyclones within the extratropical storm tracks can impinge upon the Andes and the Southern Alps of New Zealand.

The configuration of a vortex advecting within an ambient westerly airstream toward a major topographic feature is associated with three quintessential geophysical fluid dynamic settings. First the vortex itself has usually evolved from the ambient flow via some manifestation of baroclinic instability, and as it matures it tends to acquire a vertically aligned struc-

*Corresponding author. Address: Institute for Atmospheric and Climate Science, ETH, Hönggerberg HPP, 8093 Zürich, Switzerland.

e-mail: davies@atmos.umnw.ethz.ch ture. An integral aspect of this evolution is that the vortex can induce potential vorticity (PV) anomalies within the ambient flow by perturbing the latter's PV gradient, and moreover the resulting anomalies can radiate away as Rossby waves and/or interact back on the vortex itself to modify its structure and movement. Second, prior to the vortex's approach to the topography the ambient airstream can rise over and/or split and flow around the terrain to yield a quasi-steady orographically induced flow response. The nature of the response depends critically upon the structure of the incident airstream and the geometry and scale of the terrain. To a first order the dependency can be expressed in terms of a Rossby number $(\mathcal{R} o=U / f L)$ and a dimensionless height number $\left(\mathcal{F}^{-1}=N H / U\right.$, i.e. an inverse Froude number) defined by the strength $(U)$ and stratification $(N)$ of the incident flow field and the lateral scale $(L)$ and height $(H)$ of the terrain. If quasi-geostrophy prevails and $\left(\mathcal{R} o \cdot \mathcal{F}^{-1}\right) \leq 1$ the flow response features an orographic anticyclone astride the topography again with possible Rossbywave radiation of energy away from the region of the elevated terrain.

Third the juxtaposition of the vortex and the terrain is a setting for the interaction and possible 
amalgamation of the vortex and the orographically induced flow.

The processes associated with the first two settings (i.e. baroclinic instability, vortex movement on a $\beta$-plane and the orographically induced response to a steady incident airstream) can be examined in isolation, and have been the subject of intensive study. The third setting requires consideration of a vortex being advected toward and interacting with topography and is not as amenable to analysis. Statistically based climatological analyses of this third setting suggest that topography can serve as a wave-guide to deflect transient disturbances anticyclonically around major mountain ranges such as the Rockies, Himalayas and Greenland (Hsu, 1987) and the Andes Cordillera (Gan and Rao, 1994). Likewise case-study analyses and/or numerical simulations show evidence of: (a) upstream deflection of vortices approaching mountain ranges (Zehnder and Reeder, 1997; Yeh and Elsberry, 1993a; Lin et al., 1999; O'Handley and Bosart, 1996), and (b) both fragmentation of the cyclone track over the terrain and lee-side vortex redevelopment or intensification (Pascoe, 1992; Yeh and Elsberry, 1993b; O'Handley and Bosart, 1996). A related phenomenon is the occurrence of lee-cyclogenesis downstream of many major mountain ranges such as the Rockies and the European Alps. The latter has been linked to the passage of a short-wave upper-tropospheric trough toward the terrain but does not necessarily involve an upstream surface cyclone.

In the present study the focus is on the nature of interaction between the vortex and the orographicinduced flow. The procedure followed is to specify a highly idealized initial flow setting, to integrate that state forward in time using a hemispheric primitive equation model, and then to diagnose and interpret the simulated evolution. The specified initial state although idealized is nevertheless physically germane, and it is selected to help elicit the quintessential features of the interaction that can ensue in realized events.

\section{The physical setting}

The three ingredients of the selected initial state are illustrated in Figs. 1-3. They comprise a purely barotropic zonal flow of uniform vertical stratification and potential vorticity (PV) (Fig. 1), a compact and vertically coherent balanced vortex and an ellipticalshaped topographic feature (Fig. 2). Moreover the vor-

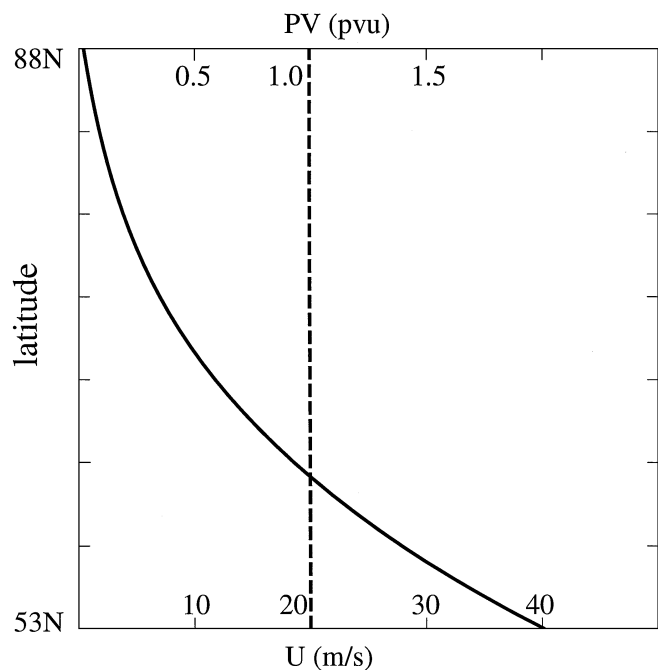

Fig. 1. Basic state latitudinal velocity profile (solid line) and $500 \mathrm{hPa}$ potential vorticity (dashed).

tex's advection by the mean flow sets in on track to intercept the topography, and the topography's lateral scale $(1500 \times 500 \mathrm{~km})$, height $(3 \mathrm{~km})$ and latitude $\left(\sim 70^{\circ} \mathrm{N}\right)$ are chosen to correspond to those of Greenland.

Figure 3 displays the initial longitude-height crosssections of the vortex and the orographic anticyclone. The zonal flow is $\sim 15 \mathrm{~m} \mathrm{~s}^{-1}$ at the latitude of these two features. The vortex is associated with a circumferential velocity of $\sim 15 \mathrm{~m} \mathrm{~s}^{-1}$ in the lower troposphere and has a perturbation surface pressure signature of $\sim-48 \mathrm{hPa}$ compared to the zonal basic state. In line with these features the vortex carries a distinct signal in its near-surface potential temperature field of $\sim 10 \mathrm{~K}$ (cf. Figs. 2b and 3a). Note that this warm-cored vortex is located poleward of the model jet. Both these features (the thermal anomaly and the position relative to the jet) bear comparison with that of intense cyclonic vortices in their mature "warm-core seclusion" phase (Shapiro and Keyser, 1990). Finally the orographic-anticyclone is associated with circumferential velocities $\left(\sim 20 \mathrm{~m} \mathrm{~s}^{-1}\right)$ that are comparable to that of the vortex, but in contrast with the vortex the underlying terrain approximates to an isentropic surface (cf. Figs. $2 b$ and $3 b$ ).

The selection of the foregoing initial state is related to the three settings referred to in the Introduction. First the barotropy and uniform PV of the ambient flow rules out the occurrence of phenomena associated with the first setting (i.e. baroclinic instability, 
a) Geopotential at $500 \mathrm{hPa}$

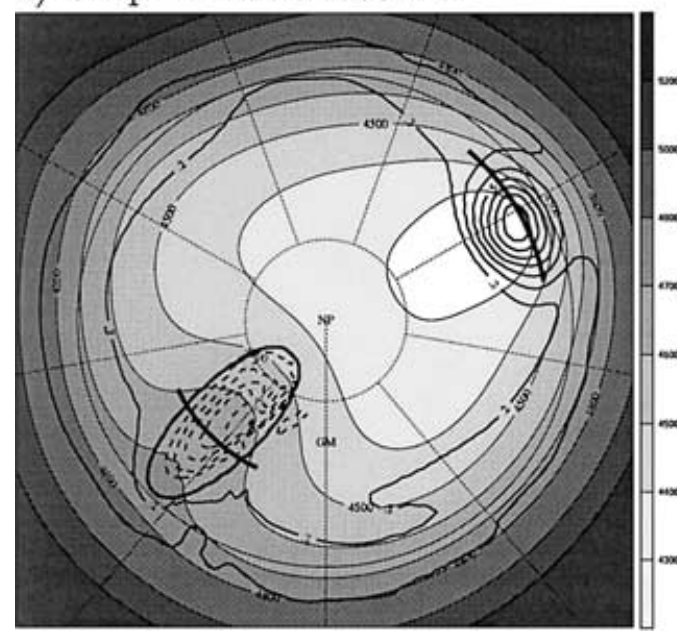

\section{b) Potential temperature}

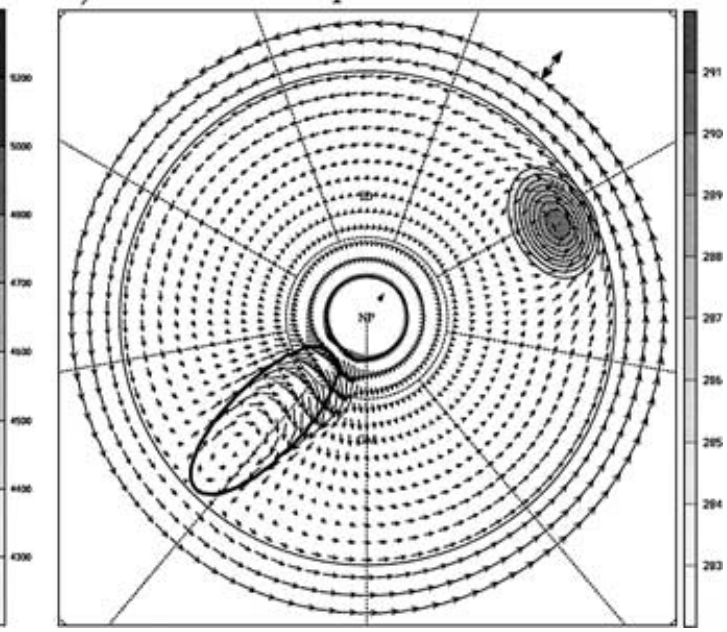

Fig. 2. Initial configuration. (a) $500 \mathrm{hPa}$ geopotential height field shaded (4200-5200 m, $100 \mathrm{~m}$ interval) and vorticity contours (interval $0.1 \times 10^{-4} \mathrm{~s}^{-1}$, negative dashed). Orography indicated by $850 \mathrm{hPa}$ contour. (b) Potential temperature $\theta$ (from $283 \mathrm{~K}, 1 \mathrm{~K}$ interval) and wind vectors (max value $40 \mathrm{~m} \mathrm{~s}^{-1}$ ) on lowest model level. (GM, Greenwich meridian; ID, international date line).
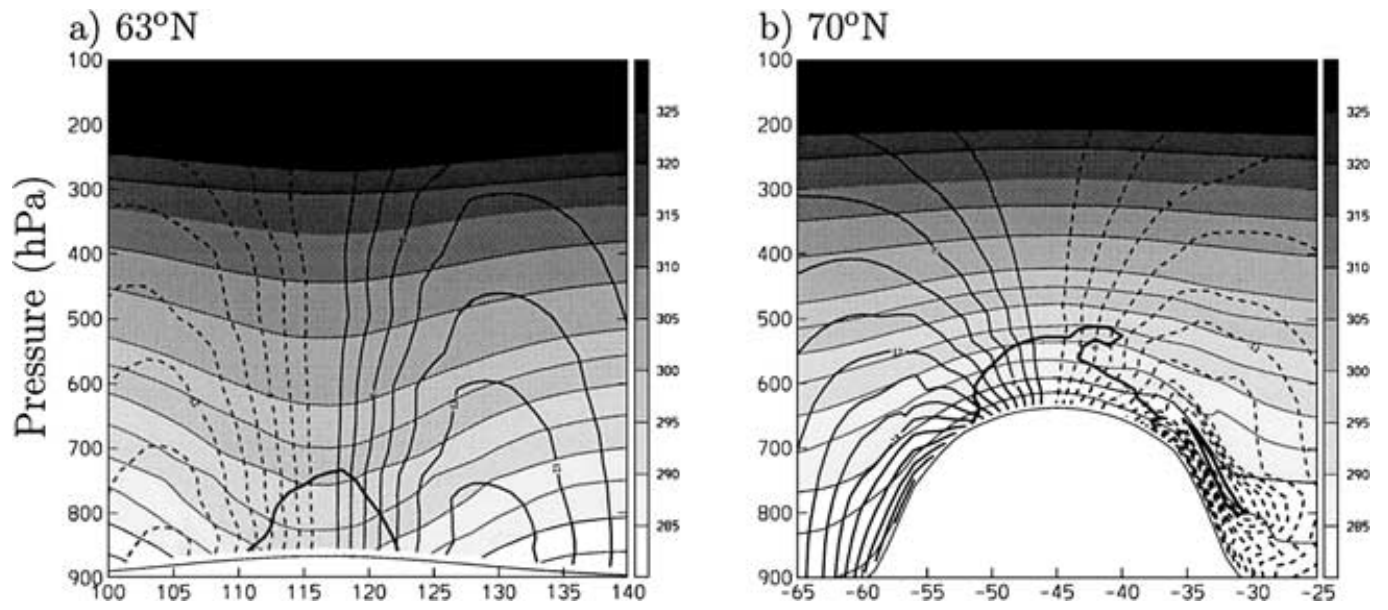

Fig. 3. Basic state cross-sections (as indicated in Fig. 2a) showing potential temperature (shaded, from $280 \mathrm{~K}, 2.5 \mathrm{~K}$ interval) and meridional wind (contour interval $2 \mathrm{~m} \mathrm{~s}^{-1}$ ) for (a) the anomaly $\left(100 \mathrm{E}-140 \mathrm{E}\right.$, vorticity contour $1.2 \times 10^{-4} \mathrm{~s}^{-1}$ bold) and (b) the mountain anticyclone $\left(65 \mathrm{~W}-25 \mathrm{~W}\right.$, vorticity contour $-0.5 \times 10^{-4} \mathrm{~s}^{-1}$ bold).

induction of PV anomalies within the ambient flow, and Rossby wave radiation). The stipulation of uniform PV is not at variance with the observed comparatively well mixed character of tropospheric PV away from the extra-tropical jet (Sun and Lindzen, 1994; Swanson et al., 1997; Davies and Rossa, 1998).

Second the strength of the ambient flow and the dimensions of the topography are associated with val- ues of $\mathcal{R} o \sim 0.1-0.5$ and $\mathcal{F}^{-1} \sim 2-3$. In this region of the $\left[\mathcal{R} o, \mathcal{F}^{-1}\right]$-parameter space the incident flow can surmount the terrain, and the dominant component of the flow is a balanced orographically induced anticyclone astride the topography with an almost isentropic underlying surface. This response can be viewed as a fission of the ambient flow's PV as the incident air parcels traverse the terrain into a 
compensating combination of reduced vorticity and enhanced stratification. Recall the absence of a significant $\theta$-anomaly over the topography (Fig. 2b). For our later discussion it is important to note that in the limit of balanced flow the nature and amplitude of this topographically induced fission depends on the PV value of the incident airstream air but not on its alignment and strength.

Third, the three ingredients of the basic state (the ambient flow, vortex and orographic anticyclone) are each finite in amplitude, and are comparable to one another and to the atmospheric counterpart systems. This ensures that the vortex-orography interaction can be highly non-linear, and allows for the interaction to display a modicum of realism.

\section{Simulated flow evolution}

\subsection{The model}

The temporal evolution of the prescribed initial state is computed with a quasi-hemispheric and adiabatic version of the hydrostatic numerical weather prediction model (EM) of the German Weather Service (see Majewski, 1991, for details of the model formulation). The model version used here is without a parametrization scheme for vertical turbulent mixing. It is therefore free of surface mixing effects and explicit vertical momentum and thermal diffusion. Also, the horizontal mixing, achieved with a fourth-order scheme on the model's $\sigma$-surfaces, is minimal in the absence of steep orography (see later).

For our present purpose we note that the model is run on a pole-centered grid and relaxed toward the initial state in a subtropically confined margin zone (ca. $20^{\circ} \mathrm{N}$ ). In the present version the model has 27 levels in the vertical and a horizontal resolution of $\sim 100 \mathrm{~km}$ in the extratropics. These values suffice to provide a reasonable representation of the vortex, the gross features of a Greenland-scale massif, and the flow evolution.

\subsection{The Evolution: description and diagnosis}

3.2.1. Eulerian features. The evolution of the geopotential and vorticity fields on the $500 \mathrm{hPa}$ surface (Fig. 4) and the potential temperature $(\theta)$ on the lowest model level (Fig. 5) fall into three overlapping phases. In a first phase ( $t \leq 150 \mathrm{~h})$ the vortex's vorticity and thermal patterns retain their compact character, although the vortex is embedded in an ambient flow of non-constant angular velocity, and the vortex advects eastward with the mean flow whilst contemporaneously experiencing a weak retardation and mild poleward drift. In a second phase $(t \sim 150-240$ $h)$ the vortex approaches and deflects anticyclonically around the topography whilst concurrently appearing to lose some of its spatial coherency. The dissolution is particularly evident in the vorticity and thermal fields. In the third phase $(t \geq 240 \mathrm{~h})$ the severely disrupted vortex recovers much of its axisymmetric structure on the lee-side. Thereafter the partially reconstituted but reduced in amplitude vortex together with a weaker forerunner are advected downstream away from the topography.

A notable feature of all three phases is that the orographic anticyclone is comparatively unperturbed throughout, although it is approached by a vortex whose velocity signal is of comparable strength. The simulated flow is adiabatic and inviscid, and hence the surface potential temperature (for which $\theta$ on the lowest model level is a rough proxy) and the potential vorticity on a free-atmosphere isentropic surface are both Lagrangian-conserved fields. Moreover, in the present setting the main "PV- $\theta$ " signal is indeed the surface $\theta$-field, and therefore its evolution provides a guide of the flow's Lagrangian structure. The successive panels of Figs. 4 and 5 suggest that air parcels associated with the incident vortex circumnavigate poleward around the topography. During the second phase they undergo strong distortion to yield a thermal filament that extends around the northern arch and also along the lee side of the mountain. In the third phase the filament is recompacted to give an axisymmetric $\theta$-signal of slightly weaker $(\sim 3 \mathrm{~K})$ strength compared with the original thermal vortex, but of a comparable spatial scale. The filament also fragments and produces a weaker and more diffuse vortex forerunner (Fig. 5, label " $\mathrm{X}$ " at $t=270 \mathrm{~h}$ ). Thus the vortex mass, defined as the fluid bound by thermal contours, is comparatively well conserved (see area covered by the vortex in Fig. 5, $150 \mathrm{~h}$ vs. $330 \mathrm{~h}$ ), and the decrease in vortical amplitude (Fig. 4) is partly explained by the fragment stripped off the main thermal vortex.

Now consider the evolution of the meridional flow component (Fig. 6) and the deformation field (Fig. 7) in the vicinity of the orography during the second and third phases. Prior to the vortex's approach to the orography their meridional velocity components exhibit maxima of $\sim 12$ and $\sim 32 \mathrm{~m} \mathrm{~s}^{-1}$ respective, whereas the approach of the vortex windward of the topography increases the meridional flow to $\sim 55 \mathrm{~m} \mathrm{~s}^{-1}$. Likewise 

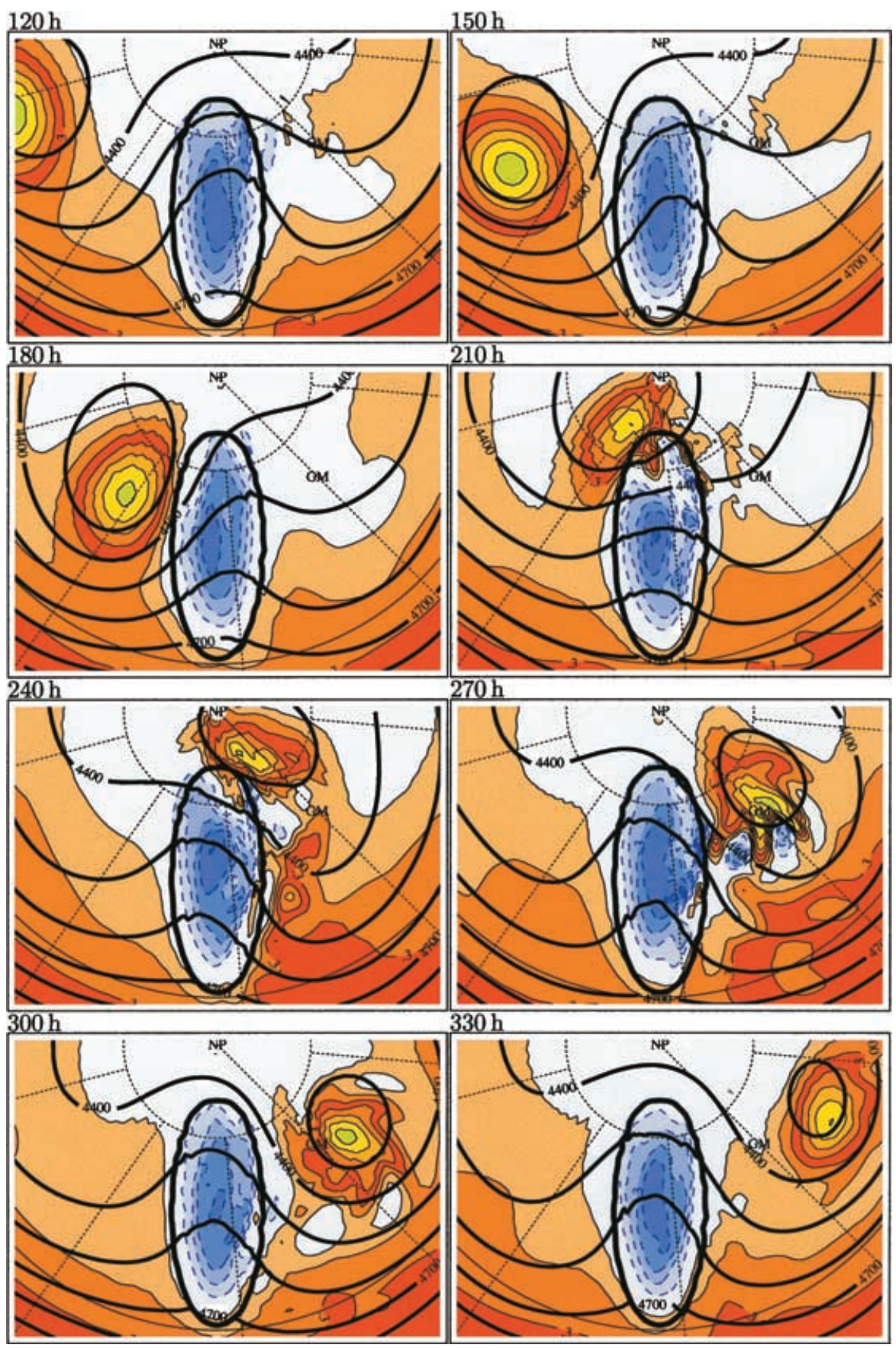

$330 \mathrm{~h}$

Fig. 4. Time sequence (120-330 h) of $500 \mathrm{hPa}$ vorticity (shaded, contour interval $0.1 \times 10^{-4} \mathrm{~s}^{-1}$, negative: blue dashed) and geopotential height field (contours as in Fig. 2a). 


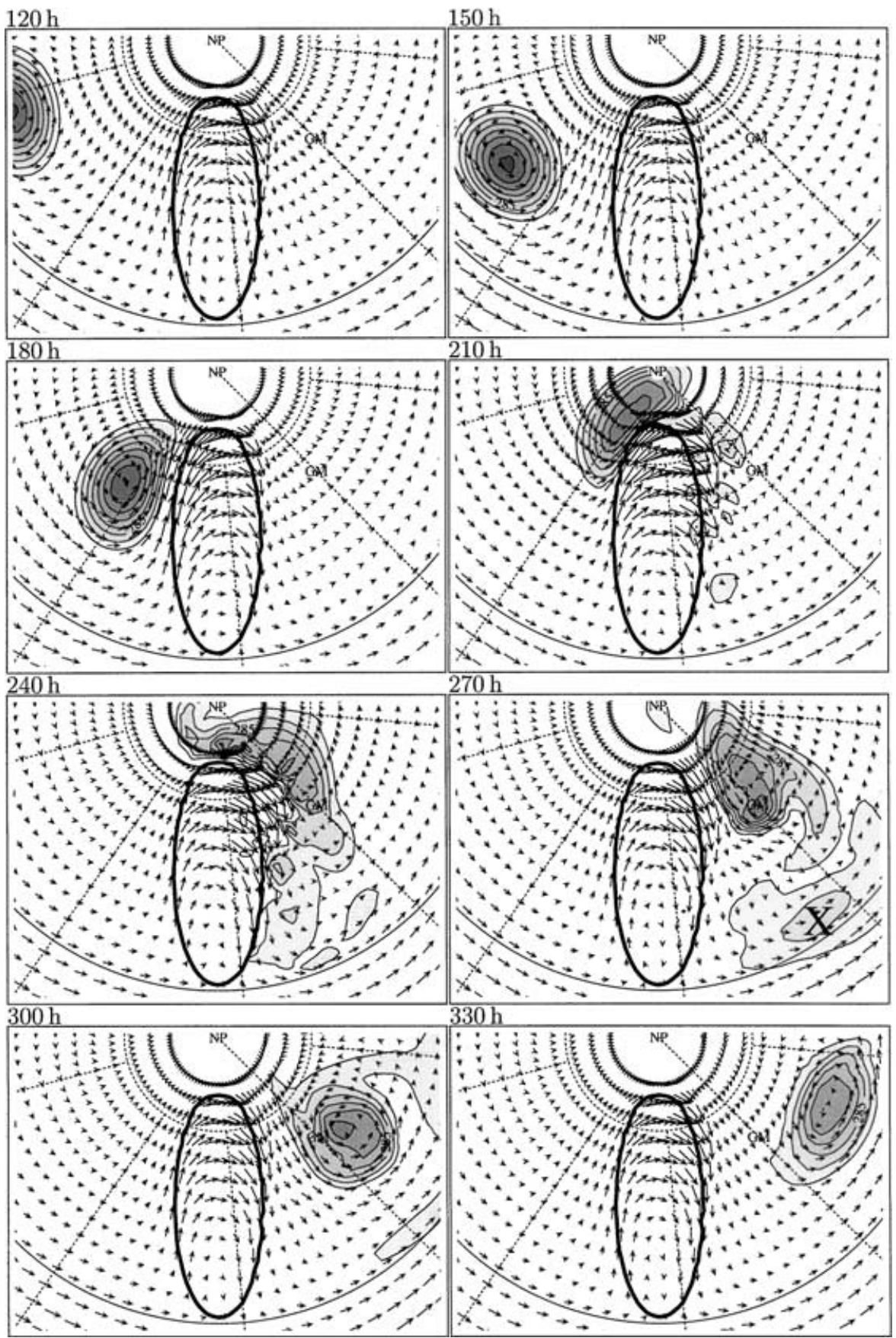

Fig. 5. Time sequence (120-330 h) of surface potential temperature and wind, analogous to Fig. $2 \mathrm{~b}$. The forerunner is labelled with "X" at $t=270 \mathrm{~h}$. 


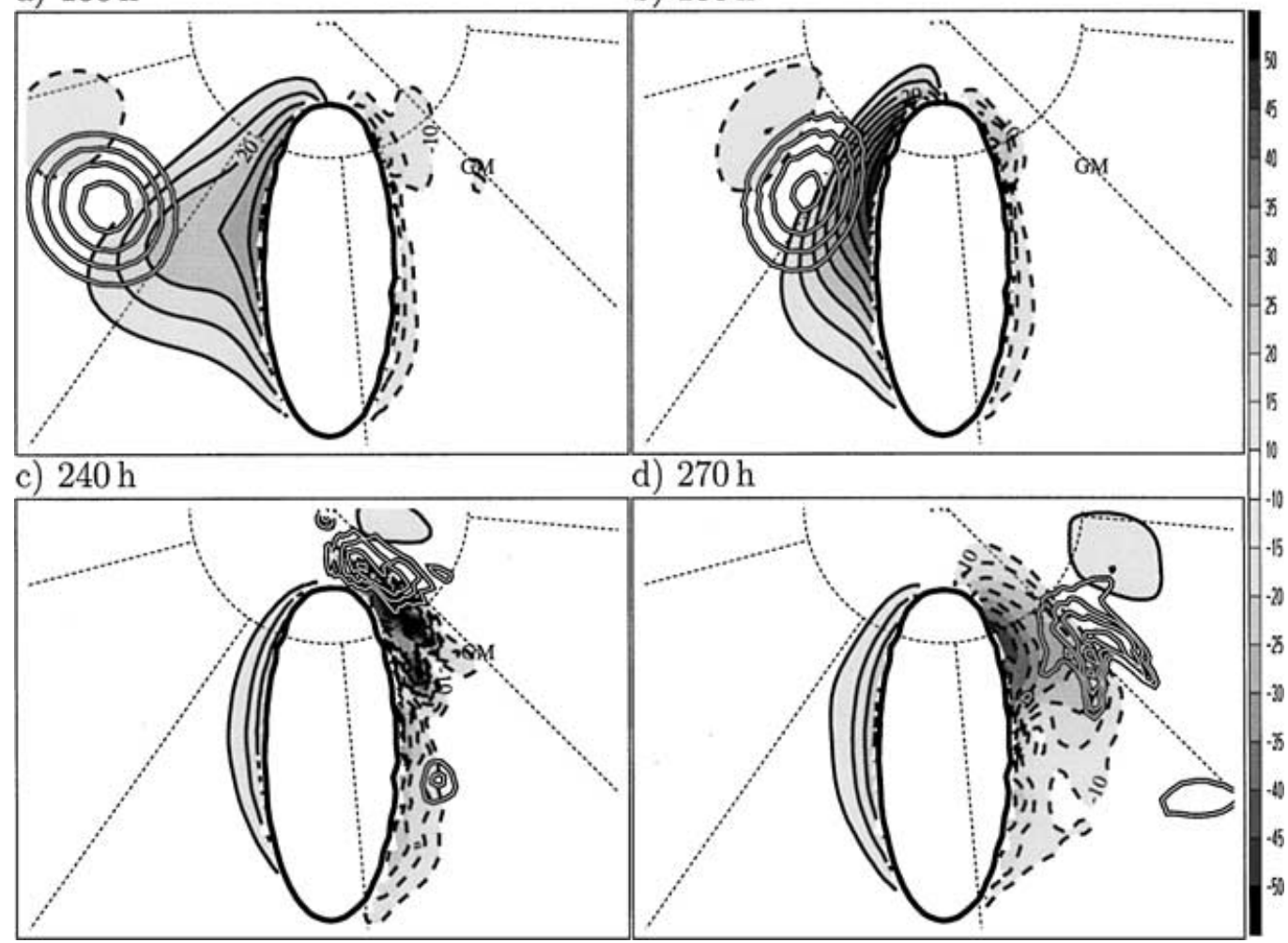

Fig. 6. $850 \mathrm{hPa}$ meridional flow component (shaded, contour interval $5 \mathrm{~m} \mathrm{~s}^{-1}$, contours less than $10 \mathrm{~m} \mathrm{~s}^{-1}$ omitted) for times (a) 150, (b) 180, (c) 240 and (d) $270 \mathrm{~h}$. Mountain contour and vorticity contours are repeated from Fig. 4 for orientation.

during recompaction the northerly flow on the leeside attains a value of $\sim-50 \mathrm{~m} \mathrm{~s}^{-1}$ (Figs. 6a-d). The accompanying low-level horizontal deformation field in the vicinity of the topography (Fig. 7) is $\sim 1.0 \times$ $10^{-4} \mathrm{~s}^{-1}$ prior to the arrival of the vortex, and would itself in isolation suffice to severely distort a passive scalar advecting past the terrain within the ambient flow (see later). The approach of the vortex increases the strength of the deformation field by a factor $\sim 5$ first on the windward side and later in the northern lee region (Figs. 7a-d).

3.2.2. Lagrangian features. The foregoing description is supported by an explicit examination of the Lagrangian evolution of the ensemble of selected air parcels using the combined trajectory and diagnosis routine of Wernli and Davies (1997). It is applied to the output of the numerical simulation accessed with a $2 \mathrm{~h}$ temporal resolution.

Four different trajectory ensembles are selected for consideration. The first corresponds to $150 \mathrm{~h}$ forward trajectories from an elliptical region initially located at $850 \mathrm{hPa}$ upstream of the orography at $t=0 \mathrm{~h}$ (Fig. 8a). The temporal evolution of several dynamical variables along these trajectories is also visualized in Fig. 9a. The results are indicative of the nature of the orographic modification of the flow prior to the approach of the vortex. These quasi-passive trajectories experience minor enhancement of the deformation (factor 3-4) due to the ambient mountain-induced flow perturbation (i.e. poleward deflection, acceleration along the northern tip of the mountain with an accompanying moderate ascent and descent). The envelope of this ensemble remains relatively unperturbed and thus reflects the passive advection and moderate shear deformation within the ambient flow.

The second ensemble is a set of $150 \mathrm{~h}$ backward trajectories of air parcels initially located at $500 \mathrm{hPa}$ directly over the orography at $t=300 \mathrm{~h}$ (Figs. $8 \mathrm{~b}$ and $9 b)$. The pattern's shape captures the essence of the anticyclonic circulation over the mountain, and the 


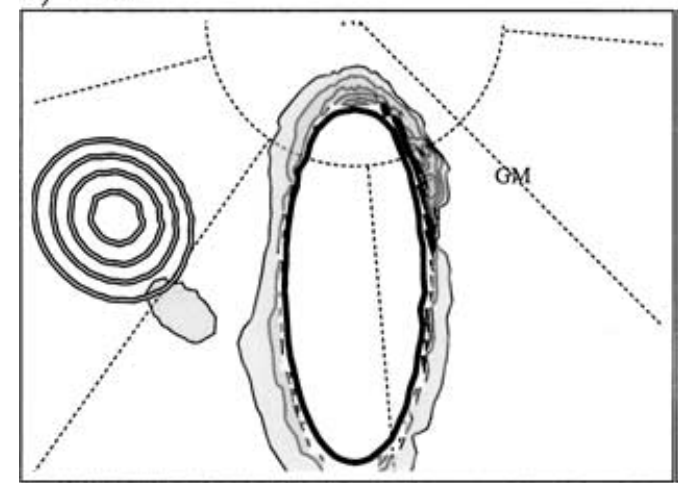

b) $180 \mathrm{~h}$

\section{c) $240 \mathrm{~h}$}
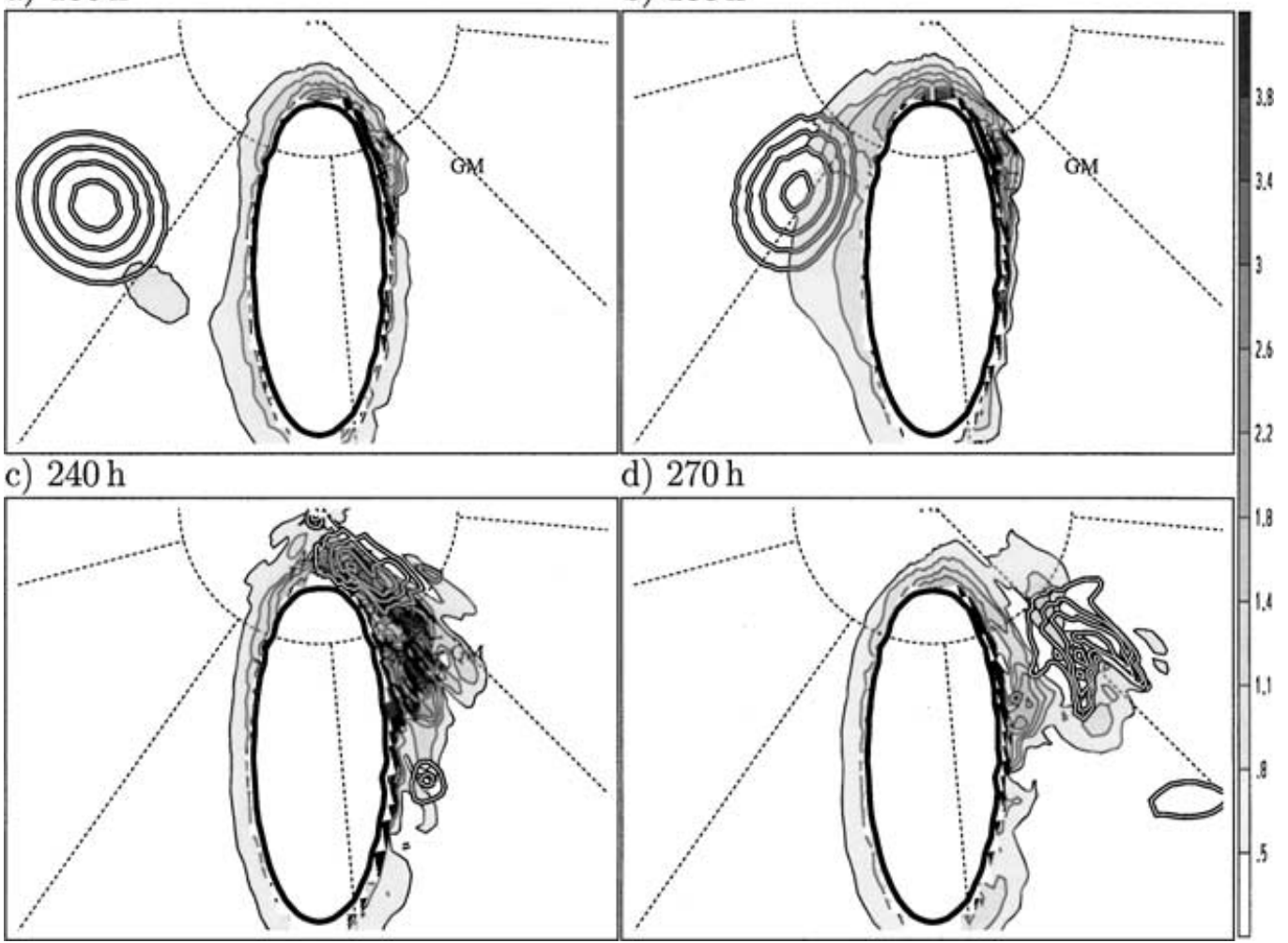

Fig. 7. $850 \mathrm{hPa}$ deformation field (shaded, contours $0.5,0.8,1.1,1.4,1.8,2.2,2.6,3.0,3.4$ and 3.8 in units of $10^{-4} \mathrm{~s}^{-1}$ ), analogue to Fig. 6.

colour variations (depicting the vorticity) provide a clear illustration of the PV fission into vorticity and stratification anomalies that is the basis for the orographically induced anticyclone.

The third ensemble is a set of $150 \mathrm{~h}$ forward trajectories of air parcels initially located at $850 \mathrm{hPa}$ within the core of the vortex at $t=150 \mathrm{~h}$ (Figs. $8 \mathrm{c}$ and 9c). Note that these parcels emanate from the same geographical location as those of the first ensemble. (The selection of the first ensemble was based upon this criterion.) The trajectories are consistent with vortex elongation on the windward side and recompaction to the lee. The air parcels within the vortex first retain their cyclonic rotation in the approach to the mountain and are then severely distorted to a filamentary form during the phase of poleward circumnavigation (i.e. at $70-80 \mathrm{~h}$ trajectory time). It is pertinent to note that the polar location of the mountain implies an enhanced curvature of the flow, and hence additional strain upon the air parcels. The shearing of the vortex sets in on the windward side and reaches its maximum slightly downwind of the mountain's axis of symmetry. Notice that an air parcel rotating within the vortex experiences much stronger deformation while in close proximity to the mountain, in comparison to the far side of the vortex. This is consistent with the non-linear velocity increase due to the mountain anticyclone. The envelope of the air parcels recovers its original shape in the lee, and a small portion of trajectories split from the main body.

The fourth ensemble (Figs. 8d and 9d) is only a sub-set of the third, and comprises those parcels that fragment from the original vortex core to form the downstream vortex forerunner.

Common features of the latter two ensembles include: (i) a large degree of coherence prior to and after the interaction period; (ii) an interaction period characterized by marked distortion in line with the enhanced deformation field, (iii) parcels that remain relatively isentropic throughout. Figures $8 c, 8 d, 9 c$ and $9 d$ 
a) ambient atmosphere $850 \mathrm{hPa}$

b) mountain anticyclone

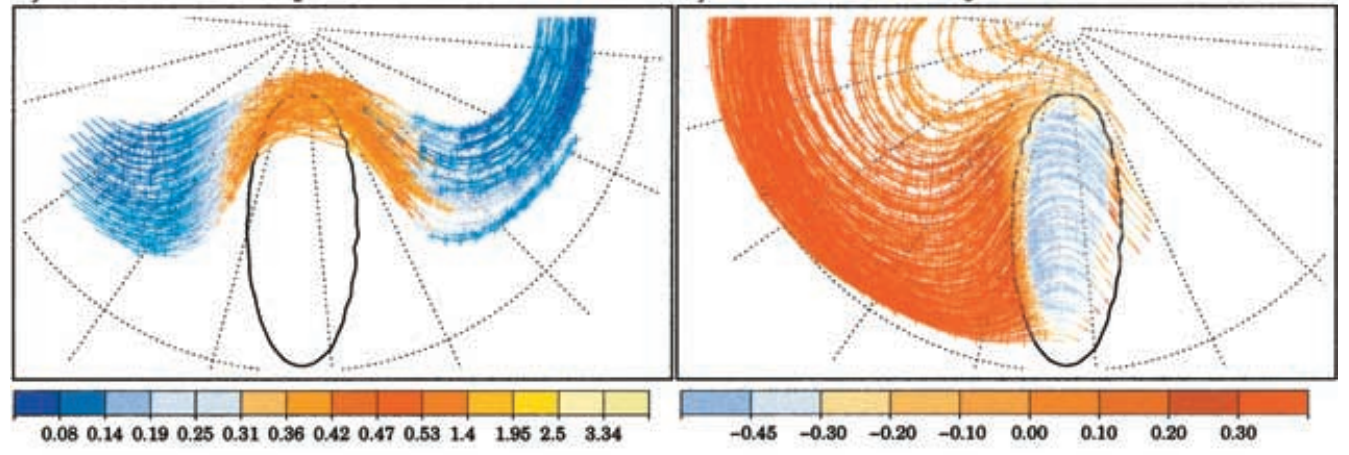

c) vortex $850 \mathrm{hPa}$

d) vortex forerunner $850 \mathrm{hPa}$

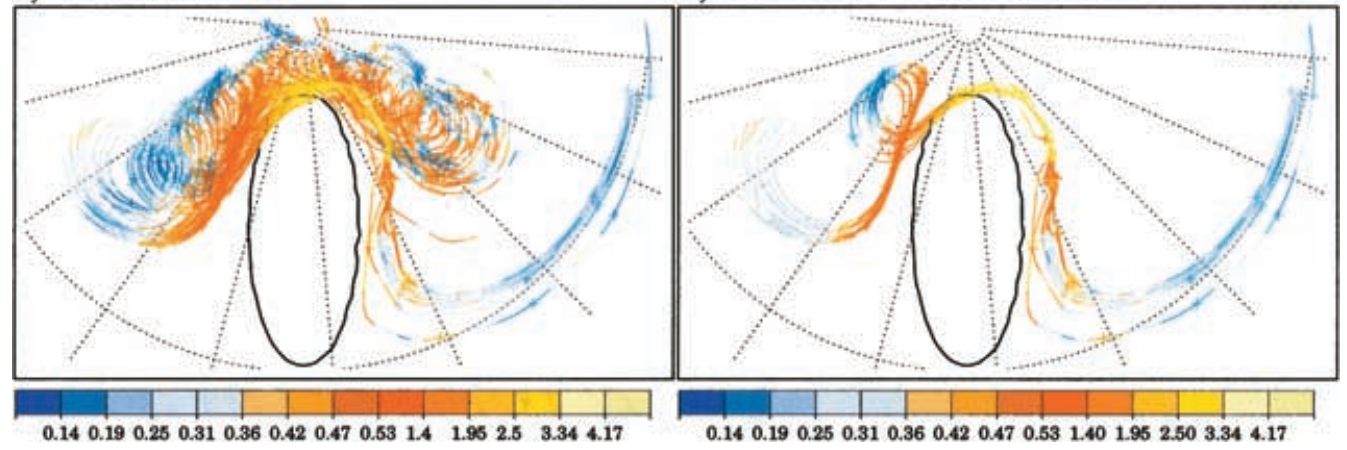

Fig. 8. $150 \mathrm{~h}$-forward trajectories started on $850 \mathrm{hPa}$ (a) within the "free atmosphere" at $t=0 \mathrm{~h}$. Colour shading: deformation $\left(10^{-4} \mathrm{~s}^{-1}\right)$, values as indicated on colour bar. Only every second trajectory is shown. (b) $150 \mathrm{~h}$-backward trajectories from mountain anticyclone (colour variable: vorticity). (c) Analogue to (a), but started on $850 \mathrm{hPa}$ from within the vortex anomaly at $t=150 \mathrm{~h}$. (d) Separate depiction of a fragment from (c). See also Fig. 9 for further details and additional traced variables.

together suggest that the tendency for fragmentation is very localized in both space and time, depending upon the exact position of an air parcel within the superposed flow fields of both vortices (cf. the large increase of variance within the ensemble). The fragment (Fig. 8d) originates as a direct consequence of a local shear maximum (deformation doubled compared to the anomaly ensemble and increased by a factor of 10 compared to the original value of $\left.\sim 0.3 \times 10^{-4} \mathrm{~s}^{-1}\right)$. The net PV loss of the fragment ensemble $(\sim 0.5 \mathrm{pvu})$ is attributable to either inaccuracies of the trajectory calculation and/or non-conservation arising from numerical diffusion. In this context consider the two terms in the PV conservation equation in the absence of diabatic processes and friction:

$$
\frac{\mathrm{D}}{\mathrm{D} t} \mathrm{PV}=\frac{\mathrm{D}}{\mathrm{D} t}\left(-g(\zeta+f) \frac{\partial \theta}{\partial p}\right)=0
$$

The variable part of the first component is the relative vorticity $(\zeta)$, and to a high measure it recovers its original value after the distortion process (Fig. 9d). It follows that the non-conservation is more likely to be related to the vertical derivative term $(\partial \theta / \partial p)$ and in particular associated with the numerical diffusion on the $\sigma$-levels that exhibit a significant vertical tilt in the vicinity of steep orography.

Computation of the analogue of the first and third ensembles (Figs. 8a and c) at an elevated level $(500 \mathrm{hPa})$ yields a similar pattern (not shown), albeit less pronounced, since the amplitudes of the anomalies tend to decay with height away from the source. More trenchantly, and consistent with the above considerations, both vorticity and PV remain constant for trajectories on a level significantly above the orography (i.e. with comparatively flat $\sigma$-surfaces). 


$$
\text { pressure(hPa) } \quad \mathrm{PV}(\mathrm{pvu}) \quad \text { deform. }\left(10^{-4} \mathrm{~s}^{-1}\right) \quad \operatorname{vorticity}\left(10^{-4} \mathrm{~s}^{-1}\right)
$$

a) Free Atmosphere $850 \mathrm{hPa}$ forward
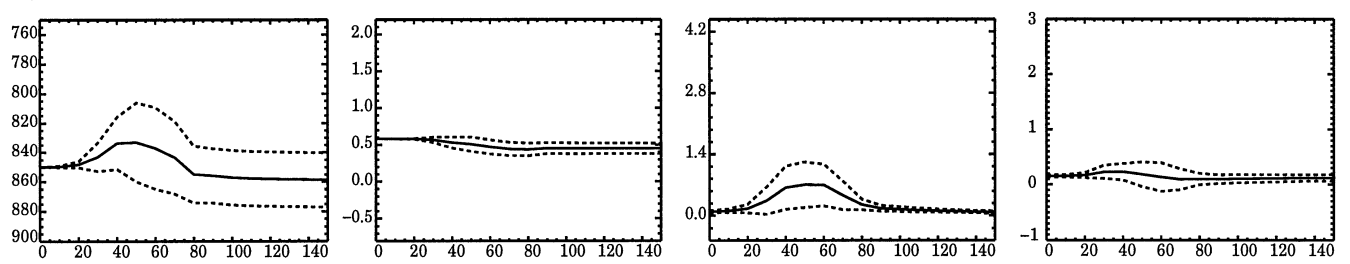

b) Anticyclone $500 \mathrm{hPa}$ backward
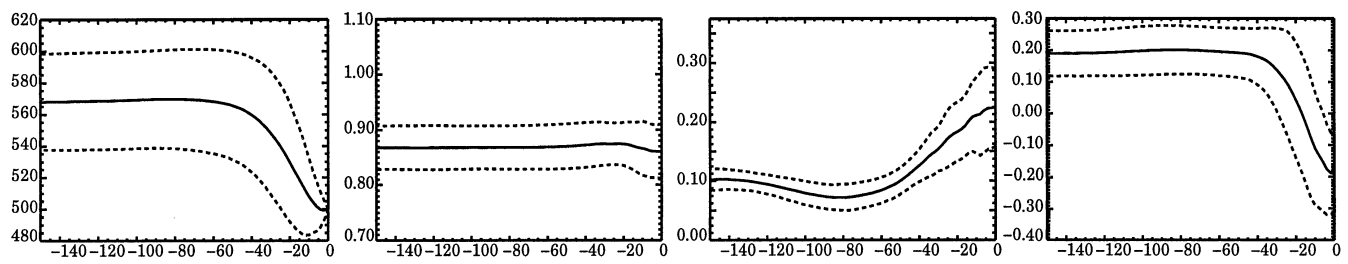

c) Anomaly $850 \mathrm{hPa}$ forward
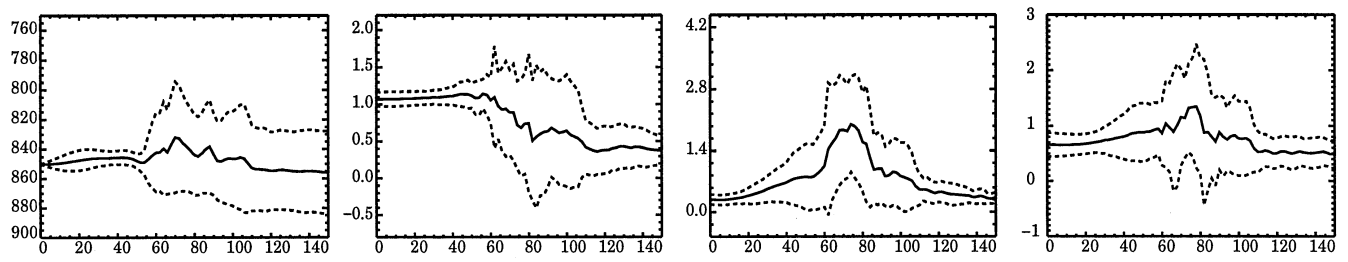

d) Fragment $850 \mathrm{hPa}$ forward
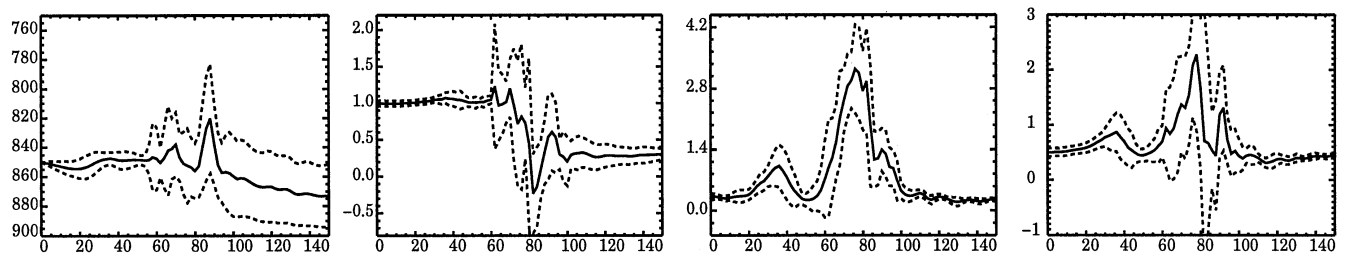

Fig. 9. $150 \mathrm{~h}$ time evolution for mean values (solid line) and standard deviations (dashed) of the indicated flow variables for the four selected trajectory ensembles $(\mathrm{a}-\mathrm{d})$ shown in Fig. 8. Columns are, respectively pressure, potential vorticity, deformation and vorticity. Notice that the range of values differs between (a, c and d) (b).

In conclusion, the contrast in the envelope of the two ensembles (Figs. 8a and c) points to the strength and role of the non-linear interaction between the vortex and the orographically induced flow. This in turn influences the location, timing and extent of vortex reconstitution, and is implicated in the parturition of the vortex's forerunner.

\subsection{Additional theoretical considerations}

Both the orographically induced anticyclone and the incident vortex are essentially balanced flow systems, and a simple phenomenological account of two aspects of the flow (vortex dissolution and recompaction and robustness of the orographic anticyclone) can be proffered from a quasi-geostrophic PV perspective.

First consider a simplified initial state formulated in Cartesian coordinates that comprises: (a) an incident uniform flow $\left(U_{0}\right)$ and stratification $(N)$, (b) an evanescent orographically induced anticyclone astride topography centred at $(x, y)=(0,0)$ and (c) a vortex in the far-field centred at $(-L, 0)$. Also for simplicity assume a circularly symmetric isentropic mountain of radius $a$ with height profile $\eta(x, y)=\eta_{\mathrm{m}}\left[1-\left(x^{2}+y^{2}\right) / a^{2}\right]^{1 / 2}$ 
with $\eta_{\mathrm{m}}=a(f / N)$, and a PV point-vortex of strength $k$ at $(-L, 0)$. For this configuration the net geostrophic streamfunction $(\psi)$ is the sum of three contributions, $\left(\psi_{a}, \psi_{b}, \psi_{c}\right)$, attributable to the above ingredients, and given respectively by

$$
\begin{aligned}
\psi_{a}= & -U_{0} y \\
\psi_{b}= & +N a^{3}\left[\left(x^{2}+y^{2}\right)+(N / f)^{2} z^{2}\right]^{-1 / 2} \text { and } \\
\psi_{c}= & -k\left[(x+L)^{2}+y^{2}+(N / f)^{2} z^{2}\right]^{-1 / 2} \\
& +(k a / L)\left[\left(x+a^{2} / L\right)^{2}+y^{2}+(N / f)^{2} z^{2}\right]^{-1 / 2} .
\end{aligned}
$$

The $\psi_{b}$ component (the contribution of the orographic anticyclone) is prescribed from Schär and Davies (1998). The two terms in the in the $\psi_{c}$ contribution represent respectively the point vortex's own signal and its mirror image of strength $(k a / L)$ located beneath the topography at $\left(-a^{2} / L, 0\right)$. Together these two terms suffice to preserve the isentropy of the terrain.

This simplified heuristic configuration is appropriate only during the first phase (i.e. $t<150 \mathrm{~h}$ ). The vortex's poleward drift during this phase can then be linked to the far-field influence of the orographic anticyclone, whereas its simulated weak zonal retardation must be accounted for by the latitudinal gradient of the ambient flow's angular velocity that the vortex experiences during its poleward drift.

The second phase is characterized by an acceleration of the vortex's poleward drift, and its rapid distortion to form a filament that arches around the topography. Both effects are consistent with the changes in the vortex's ambient field as it approaches the topography, since the $\psi_{b}$ component comprises an increase in the ambient circumferential velocity and provides a surface deformation field of $N a^{3} /\left(x^{2}+y^{2}\right)$. In principle the vortex's topographic image would enhance these effects, but the foregoing diagnosis suggests that the rapid distortion renders this a secondary effect.

In the third phase the newly formed filament's continued circumnavigation of the topography is consistent with its advection by the orographic anticyclone's circumferential velocity field. In contrast its reconstitution to form a compact vortex is at variance with the influence of the anticyclone's deformation field acting alone upon the vortex. This conundrum is resolved by recognizing the coupled effect of the filament's selfinduced motion and the influence of the ambient deformation field (Fig. 10). In isolation the elongated filament would tend to rotate cyclonically such that its leading edge would move further away from, and its trailing edge approach closer to, the terrain. In effect the realization of this rotation allows the ambient deformation field to recompact the vortex.

The foregoing process is akin to the so-called "tumbling" of a Kirchoff vortex (an elliptical vortex of uniform vorticity) in a shear flow (Meacham et al., 1990) when it periodically modulates its aspect ratio under the combined influence of its self-induced rotation and the deformation due to the ambient shear. Note that an ellipsoidal quasi-geostrophic analogue exists for the Kirchoff vortex (Meacham, 1992; Meacham et al., 1994), and that numerical simulations confirm that ellipsoidal PV vortices can be sustained as they rotate in the more general setting of the primitive equations (Fehlmann, 1997; Morgenstern and Davies, 1999). Thus the present flow development is an extension of the tumbling dynamics and serves to illustrate the partial dissolution and subsequent reconstitution
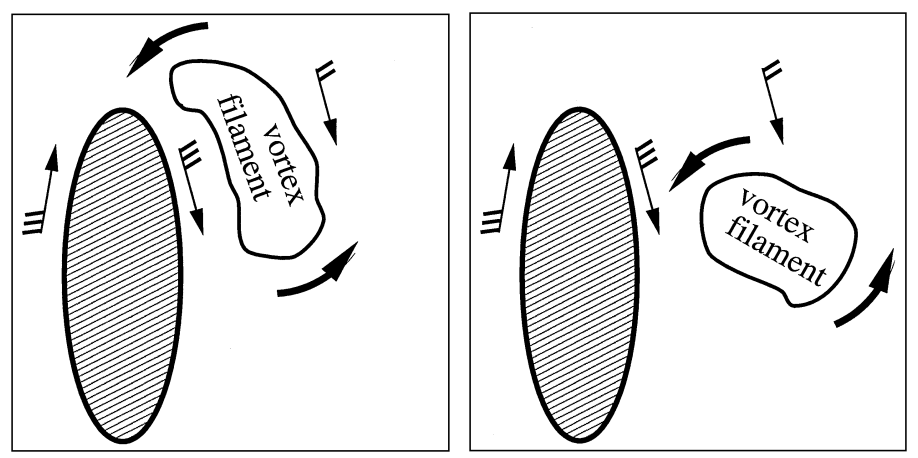

Fig. 10. Schematic of orographically induced flow (thin arrows) and self-induced velocity of the vortex filament (thick arrows) at two instances: (left) the elongated filament and (right) the re-compacted vortex. 
of a surface-based PV vortex within a highly spatially and temporally varying deformation field. Likewise the formation of a weak vortex forerunner that advects away from the terrain ahead of the reconstituted vortex has an analogue in simpler settings. It can be viewed as corresponding to the stripping of fragments from the tips of an idealized Kirchoff-like vortex (Dritschel, 1988; Meacham et al., 1990) along with the symmetrization of non-uniform filaments (Melander et al., 1986; Fehlmann 1997).

The second balanced flow interpretation concerns the robustness of the orographic anticyclone throughout the flow evolution. This is linked to the anticyclone's dependence upon the PV of the incident airstream, and its independence of the airstream's amplitude and direction. Thus the structure and amplitude of the orographic anticyclone remains unmodified by the approach of the vortex until, or rather unless, a portion of the incident vortex's anomalous potential vorticity or surface potential temperature ascends onto the topography.

A corollary of the foregoing balanced flow considerations relates to the absence of significant buoyancy or inertia-buoyancy waves over the terrain. The dominant orographic forcing of our smoothed "Greenlandscale" terrain occurs at wavelengths (>500 km) outside the regime of vertically propagating pure hydrostatic buoyancy waves and marginal to the regime for inclined longer-wavelength inertia-buoyancy waves. In effect the response is a balanced flow that is aligned predominantly along the contours of the terrain. Breakdown of balanced flow over high Greenland-scale terrain could result in significant inertia-gravity wave response via a form of non-linear scale-contraction (Trüb and Davies, 1995; Davies, 1995). However, this response is not expected to be dominant for the $\left[\mathcal{R} o, \mathcal{F}^{-1}\right]$ values of the present setting. Furthermore the model's horizontal grid length $(\sim 100 \mathrm{~km})$ is not conducive to representing or capturing gravity waves. In light of the foregoing physical and numerical considerations it is not expected that unbalanced waves will be a major feature in the present flow setting, and this is borne out in our simulations. For example there is little discernible evidence of buoyancy or inertia-buoyancy wave activity in the potential temperature field displayed in Fig. 3b. Again the most likely source region for wave initiation would be the north-eastern section of Greenland both prior to the arrival of the vortex and during its passage, but the divergence pattern for cross-sections at this latitude (not shown) display only a weak wave signal. Note also that the deformed surface "thermal" vortex in the second phase is also linked to comparable-scaled insitu balanced-flow undulations in the isentropic field that need not be attributable to unbalanced wave activity.

\section{Further remarks}

The simulated evolution of the synoptic-scale vortex's advecting towards a Greenland-scale topography presented in this study involves topographic circumnavigation, significant dissolution and substantial reconstitution of the vortex, before it is eventually advected away from the terrain within the ambient flow. This sequence of events prevails in a highly specialised and idealised flow setting, and its occurrence is governed by several factors. In particular the spatial scale of the incident flow and the terrain establishes a setting in the $\left[\mathcal{R} o, \mathcal{F}^{-1}\right]$-parameter space that, together with the spatial scale of the vortex, engenders a predominantly balanced flow evolution with the flow ascending over rather than splitting around the terrain. Furthermore the ambient setting precludes a priori both baroclinic instability and Rossby wave activity, and thereby rules out the presence of evolving fronts and cyclones and wave radiation of the topographic perturbations to the far-field.

In light of the foregoing there are two particular caveats to be attached to the study. First the simulated flow has a wide range of spatial scales that include the planetary circumpolar flow component and the scale collapse associated with the dissolution. This places severe demands upon the resolution of the numerical model, and the set-up in this study with a horizontal resolution of $\sim 1^{\circ}$ is only marginally adequate. Thus, for example, the non-conservation of a parcel's PV during the dissolution and recompaction is at least in part attributable to near grid-scale numerical diffusion.

Second the simulated sequence of events can be merely indicative, rather than representative, of the kind of processes that can occur in the neighbourhood of Greenland-scale topography. Nevertheless the results are in broad agreement with the observed phenomenon. From a climatological standpoint it is pertinent to note that the Northern Hemisphere January monthly-mean fields of vorticity on the $700 \mathrm{hPa}$ surface (Fig. 11) do show a predilection for negative anomalies (the possible vestige of orographically bound anticyclones) to occur over significant 


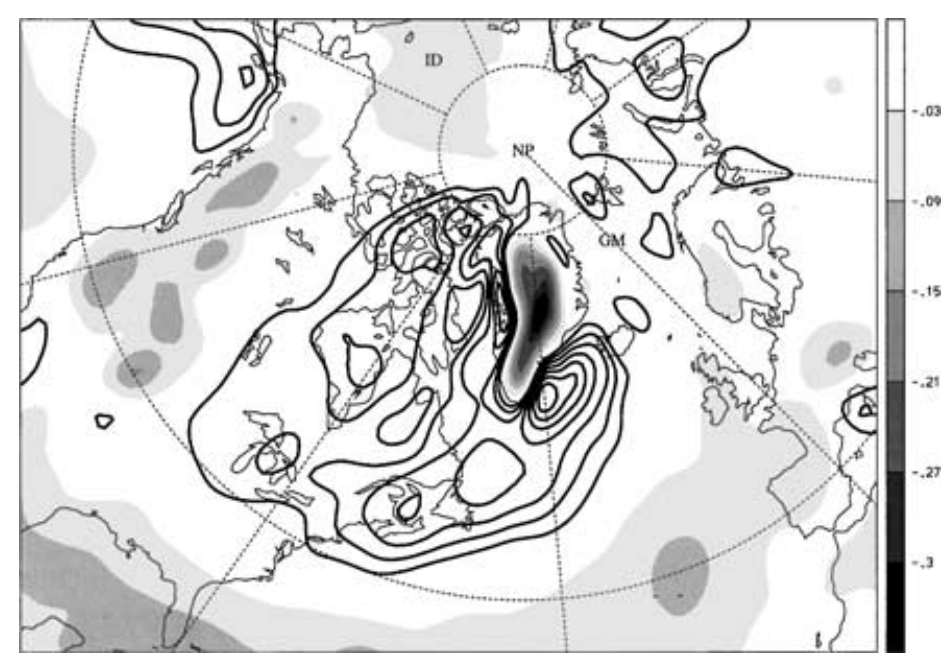

Fig. 11. Mean vorticity on 700-hPa for the winter months (DJF) for 1979-1993. Negative contour values shaded $(-0.3 \times$ $10^{-4},-0.27 \times 10^{-4},-0.21 \times 10^{-4},-0.15 \times 10^{-4},-0.09 \times 10^{-4}$ and $-0.03 \times 10^{-4} \mathrm{~s}^{-1}$ ), positive contours (black, interval $\left.0.03 \times 10^{-4} \mathrm{~s}^{-1}\right)$.

mountain ranges (cf. Hsu, 1987). From a case study standpoint the various assessments of the orographic modification of low-pressure systems noted in the Introduction are consistent with one another and with the sequence of events reported herein. An example is the following description of the evolution in the neighbourhood of the Appalachians: "the primary cyclone is first deflected northward, then dissipates over West Virginia or Pennsylvania, while a secondary center forms approximately $350 \mathrm{~km}$ away in the lee" (O'Handley and Bosart, 1996).

The limited information on the orographic influence upon an incident anticyclone (Hsu, 1987) hints at a qualitatively different behaviour to the lee. In this context note that the two-component dynamics for rapid vortex recompaction set out in the previous section would not prevail for an incident anticyclone. An elongated negative filament of $\theta$ or PV extending around the poleward tip of the terrain would rotate anticyclonically (cf. Fig. 10) and thereby serve to enhance rather than counter the distorting effect of the orographic anticyclone. Only self-induced recompaction could occur, and that could take place only after the vestige of the filament was advected away from the topography. This qualitative "prediction" is not at variance with Hsu's lag-correlation statistical analysis that points to less recompaction with a tendency to occur at a more southerly location.

An individual event is likely to be influenced by a range of other factors including flow-splitting, time- dependent frontal and upper-level modifications of the incident cyclone. For a delightful presentation of some meso-scale flow phenomena in the vicinity of Greenland see Doyle and Shapiro, (1999).

Our contention is that key ingredients of the simulated sequence of events discussed in the present study can nevertheless be present in the interaction process of the synoptic disturbance with the massif. An illustrative example is provided in Fig. 12. It shows the evolution of a vertically coherent low pressure system approaching Greenland from the south-west (Fig. 12). The low-pressure system has a minimum of $\sim 980 \mathrm{hPa}$ and is subject to mountain influence (vorticity and deformation fields) and subsequently splits into two systems, one (under the influence of the topographic waveguide) travels up the west coast, the other passes south of the tip and along the east coast of Greenland. In the ensuing development (Fig. 12), the south-eastern cyclone weakens, while the other circumnavigates on the poleward side. Finally (24.9.1993 00-12UTC), both systems appear to merge to the lee of the mountain. At the same time, a new system has developed in the west, and subsequently it too undergoes a similar cycle. This provides a hint of the frequency of their occurrence in the Greenland region. Indeed this type of evolution is consistent with the well known split of cyclone tracks in the Greenland area (Whittaker and Horn, 1984; Hsu, 1987), and a similar development has been studied by Kristjánsson and McInnes (1999). 


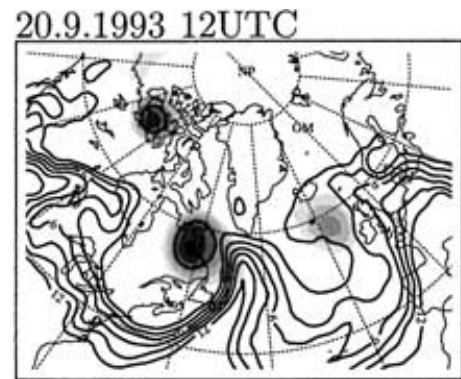

\subsubsection{UTC}

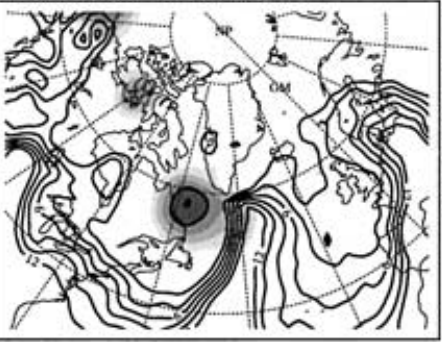

23.9.1993 12UTC

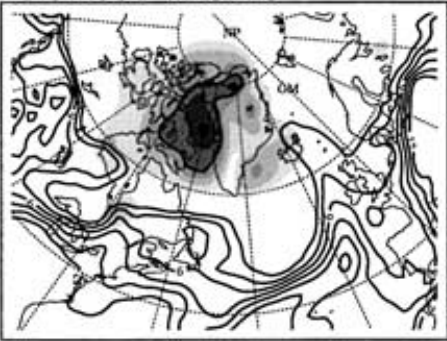

25.9.1993 00UTC

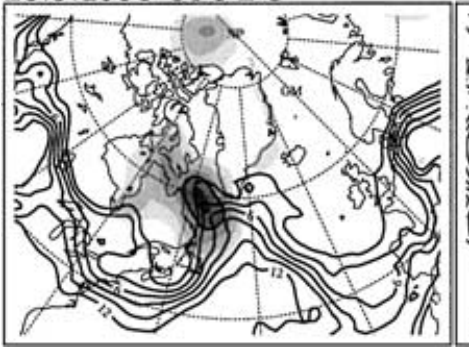

24.9.1993 00UTC

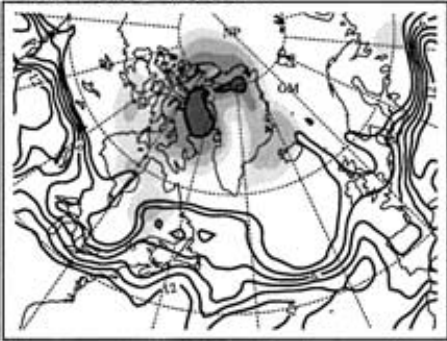

26.9.1993 00UTC

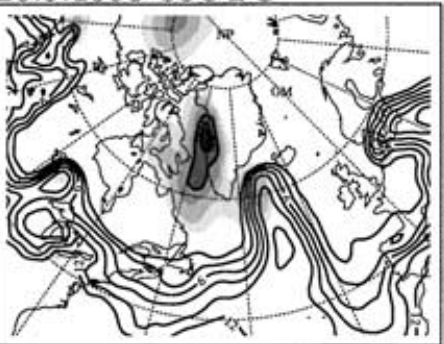

22.9.1993 12UTC

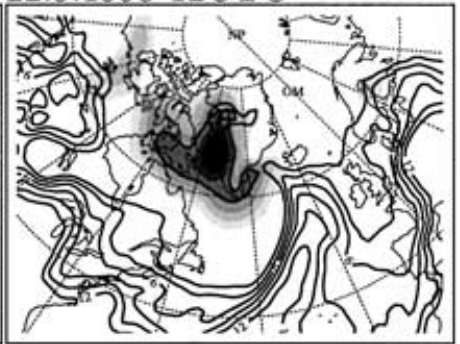

24.9.1993 12UTC

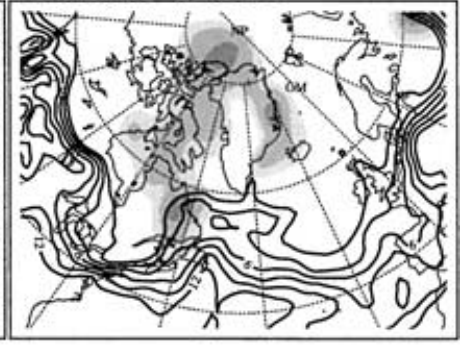

26.9.1993 12UTC

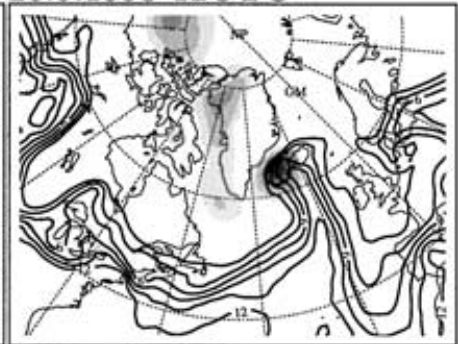

Fig. 12. Time sequence (20.9.1993 12UTC to 26.9.1993 12UTC) of ECMWF analysis fields. SLP (shaded, interval $4 \mathrm{hPa}$; max: $1002 \mathrm{hPa} ; 980$ and $990 \mathrm{hPa}$ bold) and temperature on $850 \mathrm{hPa}$ (contour interval $4 \mathrm{~K}$, from 0 to $12{ }^{\circ} \mathrm{C}$.).

The simulations presented herein illustrated the poleward circumnavigation of an incident vortex. A vortex of comparable strength but approaching from the west far to the south $(\sim 2000 \mathrm{~km})$ of the terrain would not encounter the influence of the orographically bound anticyclone and proceed eastward. A vortex approaching at an intermediate latitude $(\sim 500 \mathrm{~km})$ south of Greenland's tip, could split into two components.

Note also that the dynamics of a vortex approaching toward or located above an extended slope or isolated topographic feature is a classic setting in geophysical fluid dynamics and oceanography. In these settings the physical and dynamical scales (see e.g. Kamenkovich et al., 1996; Beismann et al., 1999) are such that the focus is on vortices moving under the influence of the $\beta$-effect (see e.g. van Geffen and Davies, 2000). In comparison to the present study the ambient flow over the terrain is often taken to be at rest, and particular consideration is then given to the mode of propagation of the vortex and its induction of flow over the topography (Sanson et al., 1999).

Finally the simulated train of events in the present study bears directly upon one aspect of the so-called "PV perspective" of synoptic development. The dynamics of the simulated evolution hinges crucially upon the orographically induced fission of the incident stream's PV into compensating vorticity and stratification signals. Comparison of the instantaneous vorticity and PV patterns during the simulated evolution 
and the corresponding mean patterns of these variables supports the concept of fission, but concomitantly underlines the necessity of accounting for the influence of quasi-isentropic orography within the PV perspective.

\section{Acknowledgments}

This study was in part conducted with funding from the NCCR Climate program of the Swiss National Science Foundation.

\section{REFERENCES}

Beismann, J. O., Kase, R. H. and Lutjeharms, J. R. E. 1999. On the influence of submarine ridges on translation and stability of Agulhas rings. J. Geophys. Res. 104, $7897-$ 7906.

Davies, H. C. 1995. Orography and the breakdown of balanced flow. In: Modern dynamical meteorology (ed. P. D. Ditlevsen). ECMWF Publications, 149-154.

Davies, H. C. and Rossa, A. M. 1998. PV frontogenesis and upper-tropospheric fronts. Mon. Wea. Rev. 126, 15281539.

Doyle, J. D. and Shapiro, M. A. 1999. Flow response to largescale topography: the Greenland tip jet. Tellus 51A, 728748.

Dritschel, D. G. 1988. The repeated filamentation of twodimensional vorticity interfaces. J. Fluid Mech. 194, 511547.

Fehlmann, R. 1997. Dynamics of Seminal PV Elements. PhD thesis. Swiss Federal Institute of Technology (ETH). Dissertation N. 12229.

Gan, M. A. and Rao, V. B. 1994. The influence of the Andes Cordillera on transient disturbances. Mon. Wea. Rev. 122, 1141-1157.

Hsu, H.-H. 1987. Propagation of low-level circulation features in the vicinity of mountain ranges. Mon. Wea. Rev. 115, 1864-1892.

Kamenkovich, V., Leonov, Y. P., Nechaev, D. A., Byrne, D. A. and Gordon, A. L. 1996. On the influence of bottom topography on the Agulhas eddy. J. Phys. Ocean. 26, 892-912.

Kristjánsson, J. E. and McInnes, H. 1999. The impact of Greenland on cyclone evolution in the North Atlantic. $Q$. J. R. Meteorol. Soc. 125, 2819-2834.

Lin, Y. L., Han, J. G., Hamilton, D. W. and Huang, C. Y. 1999. Orographic influence on a drifting cyclone. J. Atmos. Sci. 56, 534-562.

Majewski, D. 1991. The Europa-Modell of the Deutscher Wetterdienst. Numerical methods in atmospheric models. Vol. 2. European Centre for Medium Range Weather Forecasts, Shinfield Park, Reading, UK.

Meacham, S. P. 1992. Quasigeostrophic, ellipsoidal vortices in a stratified fluid. Dyn. Atmos. Oceans 16, 189-223.

Meacham, S. P., Flierl, G. R. and Send, U. 1990. Vortices in shear. Dyn. Atmos. Oceans 14, 333-386.

Meacham, S. P., Pankratov, K. K., Shchepetkin, A. F. and Zhmur, V. V. 1994. The interaction of ellipsoidal vortices with background shear flows in a stratified fluid. Dyn. Atmos. Oceans 21, 167-212.

Melander, M. V., Zabusky, S. N. J. and Styczek, A. S. 1986. A moment model for vortex interactions of the twodimensional Euler equations. 1. Computational validation of a Hamiltonian elliptic representation. J. Fluid Mech. $167,95-115$

Morgenstern, O. and Davies, H. C. 1999. Disruption of an upper-level PV-streamer by orographic and cloud-diabatic effects. Contr. Atmos. Phys. 72, 173-186.

O'Handley, C. and Bosart, L. F. 1996. The impact of the Appalachian Mountains on cyclonic weather systems. 1. A climatology. Mon. Wea. Rev. 124, 1353-1373.

Pascoe, R. 1992. Lee cyclogenesis in New Zealand-A prediction scheme. Weather and Climate 12, 40-46.

Sanson, L. Z., van Heijst, G. J. F. and Doorschoot, J. J. J. 1999. Reflection of barotropic vortices from a step-like topography. Nuovo Cim. 22, 909-929.

Schär, C. and Davies, H. C. 1988. Quasi-geostrophic stratified flow over isolated finite amplitude topography. Dynam. Atmos. Oceans 11, 287-306.

Shapiro, M. A. and Keyser, D. 1990. Fronts, jet streams and the tropopause. In: Extratropical cyclones: The Erik Palmén memorial volume. (eds. C. Newton and E. O. Holopainen). American Meteorological Society, Boston, MA, 167-191.

Sun, O. Z. and Lundzen, R. S. 1994. View of the zonal mean distribution of temperature and wind in the extratropical troposphere. J. Atmos. Sci. 51, 757-772.

Swanson, K. L., Kushner, P. J. and Held, I. M. 1997. Dynamics of barotropic storm tracks. J. Atmos. Sci. 54, 791810.

Trüb, J. and Davies, H. C. 1995. Flow over a mesoscale ridge: pathways to regime transition. Tellus 47A, 502-524.

van Geffen, J. H. G. M. and Davies, P. A. 2000. A monopolar vortex encounters an isolated topographic feature on a beta-plane. Dynam. Atmos. Oceans 32, 1-26.

Wernli, H. and Davies, H. C. 1997. A Lagrangian-based analysis of extratropical cyclones. Part I: The method and some applications. Q. J. R. Meteorol. Soc. 123, 467-489.

Whittaker, L. M. and Horn, L. H. 1984. Northern Hemispheric extratropical cyclone activity for four mid-season months. J. Climatol. 4, 297-310.

Yeh, T. C. and Elsberry, R. L. 1993a. Interaction of typhoons with the Taiwan orography. 1. Upstream track deflections. Mon. Wea. Rev. 121, 3193-3212.

Yeh, T. C. and Elsberry, R. L. 1993b. Interaction of typhoons with the Taiwan orography. 2. Continuous and discontinuous tracks across the island. Mon. Wea. Rev. 121, 32133233.

Zehnder, J. A. and Reeder, M. J. 1997. A numerical study of barotropic vortex motion near a large-scale mountain range with application to the motion of tropical cyclones approaching the Sierra Madre. Meteorol. Atmos. Phys. 64, $1-19$. 